\title{
Repair of the Lesions at DNA Synthesis Phase Induced by Irradiating the $G_{1}$ Chromosomes of Barley
}

\author{
Koji Yamamoto, Hisashi Yoshida and Hikoyuki Yamaguchi \\ Laboratory of Radiation Genetics, Faculty of Agriculture, \\ University of Tokyo, Tokyo, Japan
}

Received March 2, 1971

It has been shown that centrifugation during or immediately after irradiation increases the yield of chromosome exchanges in Tradescantia microspores, and root meristematic cells of Vicia faba or Hordeum vulgare (Sax 1943, Wolff and von Borstel 1954, Kumar and Natarajan 1966, Jacob and Wolff 1969). These findings suggested that the physically induced compression or movement of the chromosome, arising from centrifugation, resulted in reduced restitution of broken chromosomes, and consequently in an increased yield of the illegitimate rejoining, giving rise to chromosome exchanges. Wolff and von Borstel (1954) have shown that there was no increase in aberration frequency when centrifugation was applied at $10 \mathrm{~min}$ after the irradiation and concluded that the chromosome breaks have rejoined prior to the centrifugation. It has been reported previously (Yamamoto and Yamaguchi 1969) that in $G_{2}$ cells of barley root tips, the effect of centrifugation on the yield of anaphase fragment began to decrease within which centrifugation increased aberration yields prolonged with the preceding FUdR $\left(2 \times 10^{-7} \mathrm{M}\right)$ treatment. These data were interpreted as indicating that repair of the chromosomal lesions induced by $\gamma$-rays in $G_{2}$ cells is completed in a short period from 14 to $22 \mathrm{~min}$ after irradiation and possibly requires DNA synthesis.

The present work was undertaken to estimate the time necessary for repair of the chromosome lesions produced by irradiating $G_{1}$ cells and to get some information about the role of the intervening DNA synthesis (S) between the irradiation and the observation of chromosome aberrations.

\section{Material and methods}

Seeds of barley (Hordeum vulgare, cultivar Ehimehadaka No. 1, hexa-stichous, hull-less) were germinated in shaking culture $(20$ seeds per $\mathrm{L}$ tube with $3 \mathrm{ml}$ of water; 50 cycles $/ \mathrm{min}$ ) at $25^{\circ} \mathrm{C}$. Cells in the primary root tips started the first mitosis with a partial synchronization. Maximum number of anaphase cells in a root meristem was obtained at 31-32 hours after the shaking culture began.

Germinating seeds were irradiated with ${ }^{137} \mathrm{Cs}-\gamma$-rays at the 20 th hour after the initiation of shaking culture. Seeds, which received a dose of $198 \mathrm{R}(66 \mathrm{R} / \mathrm{min})$, were centrifuged at various time after the irradiation. Centrifugations were always carried out at $3000 \mathrm{rev} / \mathrm{min}$ (ca. $1500 \times \mathrm{g}$ ) for $4 \mathrm{~min}$ at room temperature unless otherwise stated. 
At the 12th hour after the irradiation, root tips were fixed in 3 parts of absolute ethanol and 1 part of glacial acetic acid. After hydrolysis in $\mathrm{N} \mathrm{HCl}$ at $60^{\circ} \mathrm{C}$, they were stained in Feulgen reagent and squashed on microslides. Anaphase cells were scored for chromosome aberrations.

In order to estimate the duration of $\mathrm{S}$ phase, seeds were incubated in ${ }^{3} \mathrm{H}$-thymidine solution $(2 \mu \mathrm{Ci} / \mathrm{ml})$ for $30 \mathrm{~min}$ at various time between 19 and 31 hours after the beginning of shaking culture. After washing in distiled water, the seeds were continued to culture in unlabeled thymidine solution $\left(4 \times 10^{-5} \mathrm{M}\right)$ and fixed at 32 hours after the beginning of shaking culture. Squash preparations were made by Feulgen procedures and the cover glasses were removed on dry ice. The slide was dipped in SAKURA NR-M2 liquid emulsion and developed with Konidol X after the exposure for 3 weeks.

Irradiated seeds were also used for an autoradiographic experiment. Seeds were irradiated at 19.75 hour after the shaking culture began. Immediately after centrifugation was applied for $6 \mathrm{~min}$ at $30,60,120$, or $390 \mathrm{~min}$ after the irradiation, seeds were cultured for $30 \mathrm{~min}$ in solution containing $2 \mu \mathrm{Ci} / \mathrm{ml}$ of tritiated thymidine. After washing in distiled water, they were continued to culture in unlabeled thymidine solution $\left(4 \times 10^{-5} \mathrm{M}\right)$ and fixed at 32 hour after the beginning of shaking culture. Autoradiographs were made by the procedure mentioned above. Tritiated thymidine ( $25 \mathrm{Ci} / \mathrm{mM}$ ) was purchased from The Radiochemical Center, England.

\section{Results}

Immediately after irradiation, seeds were centrifuged for $4 \mathrm{~min}$ at 1790, 4030, or $7160 \times \mathrm{g}$ at $0^{\circ} \mathrm{C}$. As shown in Fig. 1, bridge-type aberrations were rare in the used material, and only fragment-type increased drastically with post-irradiation centrifugation. The yield increased linearly with increasing centrifugal force. In no-irradiated seeds, centrifugation alone produce no effect. Since centrifugation at $7160 \times \mathrm{g}$ approximately doubled the frequency of chromosome aberrations, it is indicated that more than $50 \%$ of the primary chromosomal lesions produced with $198 \mathrm{R}$ undergo repair.

The effects of pre- and post-irradiation centrifugation (ca. $1500 \times \mathrm{g}$ ) on the yield of $\gamma$-ray-induced chromosomal aberrations are shown in Table 1 and Fig. 2. When irradiation followed centrifugation, there was no increase in aberration frequency. Increase in frequency of fragments was found even when centrifugation was applied 90 min after irradiation ( $\mathrm{t}=2.85$, significant at $1 \%$ level). This result is interpreted as indicating that there has been a time lag of more than 90 minutes before the rejoining of most chromosome breaks. The autoradiographic experiment showed that irradiated $G_{1}$ cells have already progressed into $S$ phase when the effect of post irradiation centrifugation began to decrease (Fig. 2). But it is necessary to perform an autoradiographic experiment in which irradiated and centrifuged seeds were cultured in tritiated thymidine solution for the estimation of exact time of repair.

In order to clarify the relationship between the onset of DNA synthesis (i.e., chromosome duplication) and the repair of chromosome lesions, labelling with ${ }^{3} \mathrm{H}$ - 


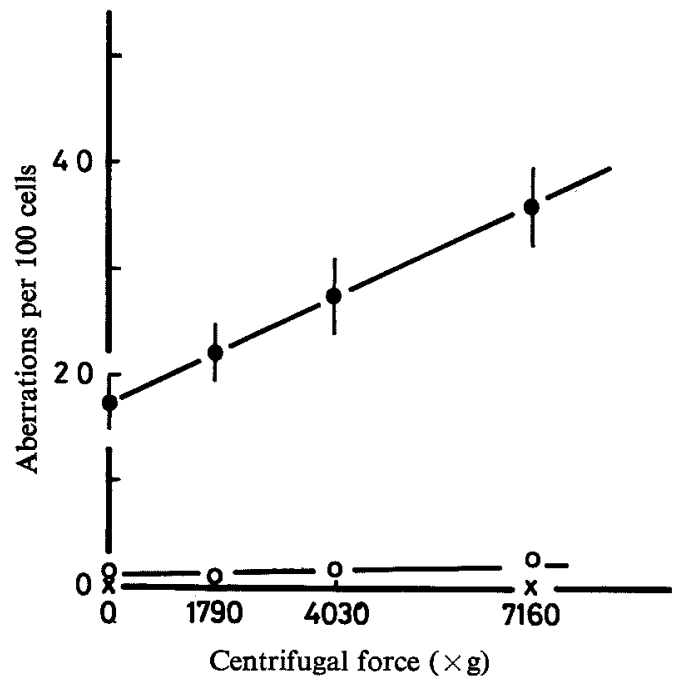

Fig. 1. Effect of post-irradiation centrifugation on the yield of $\gamma$-ray-induced anaphase fragments $(-\longrightarrow)$ and bridges ( - ). $\times$; no-irradiation. More than 210 anaphase were analyzed for each point.

Vertical lines show standered errors. thymidine was performed immediately after centrifugation at $3000 \mathrm{rev} / \mathrm{min}$ for $6 \mathrm{~min}$. The results were summarized in $\mathrm{Ta}$ bles 2 and 3 . At 60 or $120 \mathrm{~min}$ after irradiation, 9 or $48 \%$ of cells have progressed into $\mathrm{S}$ phase respectively. The aberration yield in these cells corresponded to that in the cells centrifuged at 390 min after irradiation. On the other hand, the yield in the unlabeled anaphase cells agreed with the yield in the cells centrifuged at $30 \mathrm{~min}$ after irradiation. In Table 3 , it is clear that an increased yield resulted when the irradiated cells are centrifuged before the onset of DNA synthesis, and that the repair was completed as soon as the cells progressed into the $\mathrm{S}$ phase.

Table 1. Effect of centrifugation on the frequencies of chromosome aberrations induced by $\gamma$-rays (198 R)

\begin{tabular}{c|c|c|c}
\hline \hline $\begin{array}{c}\text { Time after } \\
\text { irradiation }\end{array}$ & $\begin{array}{c}\text { Cells } \\
\text { scored }\end{array}$ & $\begin{array}{c}\text { Fragments } \\
(\% \pm \text { s.e. })\end{array}$ & $\begin{array}{c}\text { Bridges } \\
(\%)\end{array}$ \\
\hline-6 (min) & 280 & $15.7 \pm 2.4$ & 2.2 \\
4 & 280 & $25.0 \pm 3.0$ & 6.0 \\
30 & 200 & $26.5 \pm 3.6$ & 3.0 \\
60 & 210 & $24.8 \pm 3.4$ & 2.0 \\
90 & 280 & $24.6 \pm 3.0$ & 2.1 \\
120 & 280 & $21.1 \pm 2.7$ & 2.9 \\
180 & 280 & $20.0 \pm 2.7$ & 1.8 \\
240 & 280 & $18.9 \pm 2.6$ & 3.5 \\
300 & 280 & $16.8 \pm 2.4$ & 1.8 \\
360 & 300 & $17.7 \pm 2.4$ & 2.5 \\
420 & 280 & $16.1 \pm 2.4$ & 2.5 \\
480 & 280 & $12.5 \pm 2.0$ & 1.1 \\
540 & 280 & $16.4 \pm 2.4$ & 2.9 \\
$\gamma$-rays (198 R) & 570 & $14.9 \pm 1.6$ & 1.9 \\
Centrifugation & & 0 & 0 \\
(3000 rev/min, 4 min) & 280 & & \\
\hline
\end{tabular}




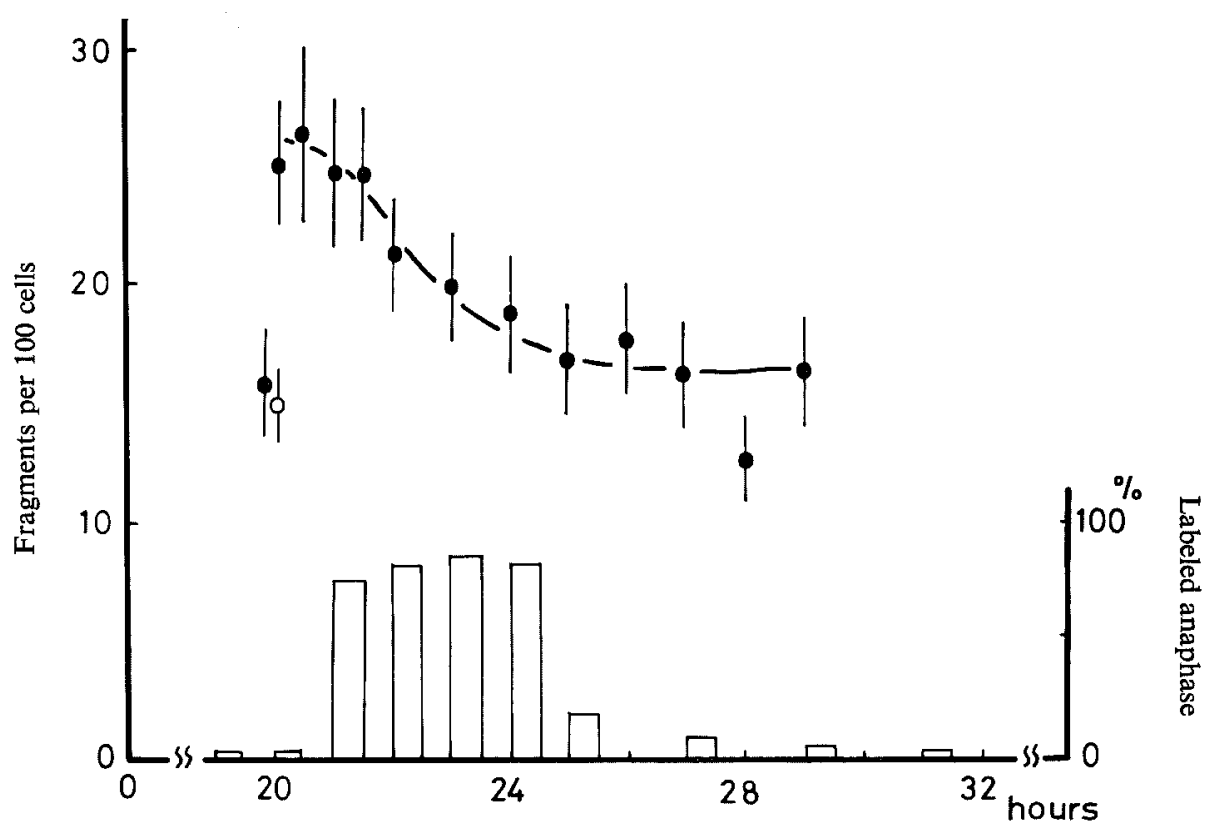

Time after the onset of germination

Fig. 2. Effects of pre- and post-irradiation centrifugation on the yield of anaphase fragments. Aberration yeild with only irradiation $(O)$. Aberration yeilds with irradiation plus centrifugation

(•). Percent of anaphse cells labeled with ${ }^{3} \mathrm{H}$-thymidine are also shown in figure.

Table 2. Effect of centrifugation performed at various time after irradiation on the yields of chromosome aberrations

\begin{tabular}{|c|c|c|c|c|c|c|c|c|}
\hline \multirow{2}{*}{$\begin{array}{c}\text { Time } \\
\text { after } \\
\text { irradia- } \\
\text { tion } \\
\text { (stages) }\end{array}$} & \multirow[b]{2}{*}{$\begin{array}{l}\text { Percent of } \\
\text { labeled } \\
\text { anaphase }\end{array}$} & \multicolumn{3}{|c|}{ Labeled anaphase } & \multicolumn{3}{|c|}{ Unlabeled anaphase } & \multirow{2}{*}{$\begin{array}{c}\text { Total } \\
\text { Fragments } \\
\text { Anaphases }\end{array}$} \\
\hline & & $\begin{array}{c}\text { Number } \\
\text { of } \\
\text { anapha- } \\
\text { ses }\end{array}$ & $\begin{array}{c}\text { Number } \\
\text { of } \\
\text { fragments }\end{array}$ & $\begin{array}{c}\text { Number } \\
\text { of } \\
\text { bridges }\end{array}$ & $\begin{array}{c}\text { Number } \\
\text { of } \\
\text { anapha- } \\
\text { ses }\end{array}$ & $\begin{array}{l}\text { Number } \\
\text { of } \\
\text { fragments }\end{array}$ & $\begin{array}{c}\begin{array}{c}\text { Number } \\
\text { of } \\
\text { bridges }\end{array} \\
\end{array}$ & \\
\hline $\begin{array}{l}30 \mathrm{~min} \\
\left(\mathrm{G}_{1}\right)\end{array}$ & 2.7 & 4 & 0 & 0 & 146 & $\begin{array}{c}47 \\
(32.2 \%)\end{array}$ & $\begin{array}{l}3 \\
(2 \%)\end{array}$ & $\begin{array}{c}47 / 150 \\
(31.6 \%)\end{array}$ \\
\hline $\begin{array}{l}60 \\
\text { (late } \mathrm{G}_{1} \text { ) }\end{array}$ & 9.2 & 23 & $\begin{array}{c}5 \\
(21.7 \%)\end{array}$ & 0 & 227 & $\begin{array}{c}73 \\
(32.2 \%)\end{array}$ & $\begin{array}{c}7 \\
(3 \%)\end{array}$ & $\begin{array}{c}78 / 250 \\
(31.2 \%)\end{array}$ \\
\hline $\begin{array}{l}120 \\
\text { (early S) }\end{array}$ & 48.0 & 48 & $\begin{array}{c}8 \\
(16.7 \%)\end{array}$ & 0 & 52 & $\begin{array}{c}16 \\
(30.8 \%)\end{array}$ & $\begin{array}{c}2 \\
(4 \%)\end{array}$ & $\begin{array}{c}24 / 100 \\
(24 \%)\end{array}$ \\
\hline $\begin{array}{l}390 \\
\left(\text { early } G_{2}\right)\end{array}$ & 12.0 & 18 & $(16.7 \%)$ & 0 & 132 & $\begin{array}{c}29 \\
(22.0 \%)\end{array}$ & $(0.7 \%)$ & $\begin{array}{c}32 / 150 \\
(21.3 \%)\end{array}$ \\
\hline
\end{tabular}

Table 3. Effect of centrifugation performed before or after the onset of DNA synthesis on the yield of $\gamma$-ray-induced chromosome aberrations

\begin{tabular}{l|c|c|c}
\hline \hline \multicolumn{1}{c|}{ Centrifugation } & $\begin{array}{c}\text { Cells } \\
\text { scored }\end{array}$ & $\begin{array}{c}\text { Fragments } \\
(\% \pm \text { s.e. })\end{array}$ & $\begin{array}{c}\text { Bridges } \\
(\%)\end{array}$ \\
\hline Before the onset of S phase $^{\mathrm{a}}$ & 425 & $32.0 \pm 2.7$ & 2.8 \\
After the onset of S phase & 225 & $20.0 \pm 3.0$ & 0.5 \\
$\gamma$-Rays (198 R) only & 280 & $21.4 \pm 2.8$ & 2.8 \\
No-irradiation & 360 & $2.0 \pm 0.7$ & 0 \\
No-centrifugation & & & \\
\hline
\end{tabular}




\section{Discussion}

In addition to a previous paper with $G_{2}$ cells (Yamamoto and Yamaguchi 1969), the present experiments suggest that there exist two steps, which are detectable with post-irradiation centrifugation, in the repair process of $\gamma$-ray-induced chromosome lesions. The first step is the period in which the post-irradiation centrifugation increases the yield of chromosome aberrations, that is, the irradiated cells are probably preparing for the repair of lesions. The second step is the period in which the post-irradiation centrifugation decreases its effect on the aberration yield, that is, the lesions are probably repairing enzymatically. When middle or late $G_{1}$ cells are irradiated, the first step goes on until the cells progressed into the following $S$ phase. The facts that the lesions induced in $G_{1}$ cells repair immediately after the progression into $S$ phase and that the observed fragments are B" type aberration, suggest that the lesions have to repair before the part of chromosome having lesions duplicated in $S$ phase. It is supposed that the $G_{1}$ cells in the first mitotic cycle after seeds soaking lack to critical factor necessary to accomplish the repair of $\gamma$-ray-induced chromosome lesions and an appearance of such factor coincides with the progression of cells from $G_{1}$ to $S$ phase. It can readily be imagined that the factor involves in DNA synthesis.

In a previous paper (Yamamoto and Yamaguchi 1969), it has been shown that in $\mathrm{G}_{2}$ cells, the first step of repair process goes on about $14 \mathrm{~min}$ and the second step completes in the following several minutes. It has to be concluded, thus, that the factor required for the repair still remained after cells have progressed from $S$ to $G_{2}$. When $G_{2}$ cells were irradiated in a presence of $2 \times 10^{-7} \mathrm{M} F U d R$ which inhibits the production of a precursor (thymidine triphosphate) of DNA, the first step prolonged until the effect of FUdR was counteracted by thymidine. These findings strongly support the view that DNA synthesis is a requirement of the repair of chromosome aberrations after irradiation.

Dose fractionation can reveal the repair time of chromosome breaks due to a change of the yield of two-hit chromosome exchanges. Thus many investigators reported the time required for the rejoining of chromosome breaks after irradiation (see, Wolff 1967 as review). Observing anaphase bridges after fractionated irradiations, Ichikawa et al. (1965) showed that rejoining of chromosome breaks was completed within $30 \mathrm{~min}$ after irradiation of barley root rips. It is impossible now to explain the discrepancy between their results and ours obtained with postirradiation centrifugation. The investigation of the difference between results obtained with each method must be the subject of further research in order to clarify the mechanism of rejoining of broken chromosome.

\section{Summary}

$\mathrm{G}_{1}$ cells in primary roots of Hordeum vulgare were gamma-irradiated with a

a Unlabeled anaphases centrifuged at 30,60 or 120 min after irradiation (Table 2) were pooled.

b Labeled anaphases centrifuged at 30,60 or $120 \mathrm{~min}$ after irradiation and total anaphases centrifuged at $390 \mathrm{~min}$ after irradiation (Table 2) were pooled. 
dose of $198 \mathrm{R}$ and centrifuged for $4 \mathrm{~min}$ at $1500 \times \mathrm{g}$ at various time after irradiation. Post-irradiation centrifugation increased the frequency of anaphase fragments. The significant increase in frequency was found to be possible only before the progression of the irradiated cells from $G_{1}$ into $S$. The best hypothesis to account for the obtained results seems to be that the $G_{1}$ cell in the first mitotic cycle after seed germination does not contain the factor(s), probably enzyme(s), necessary to accomplish repair of radiation-induced lesions and also chromosome duplication.

\section{References}

Ichikawa, S., Ikushima, T. and Nishiyama, I. 1965. Two kinds of chromosome rejoinings in Xrayed two-rowed barley. Radiation Botany 5: 513-523.

Jacob, K. M. and Wolff, S. 1969. The effect of post-irradiation centrifugation on chromosome aberration in Vicia faba. Int. J. Radiat. Biol. 15: 519-523.

Kumar, S. and Natajan, A. T. 1966. The mechanism of the effect of post-irradiation centrifugation on the yield and kinetics of radiation induced chromosome aberrations in bareley. Genetics 53: 1065-1069.

Sax, K. 1943. The effect of centrifuging upon the production of X-ray induced chromosomal aberrations. Proc. Natl. Acad. Sci. (U.S.) 29: 18-25.

Wolff, S. 1968. Chromosome aberrations and the cell cycle. Radiation Res. 33: 609-619.

- and von Borstel, R. C. 1954 . The effects of pre- and post-irradiation centrifugation on the chromosomes of Tradescantia and Vicia. Proc. Natl. Acad. Sci. (U.S.) 40: 1138-1141.

Yamamoto, K. and Yamaguchi, H. 1969. Inhibitory effect of 5-fluorodeoxyuridine on the repair of $\gamma$-ray-induced lesions in barley chromosome. Mutation Res. 8: 424-427. 